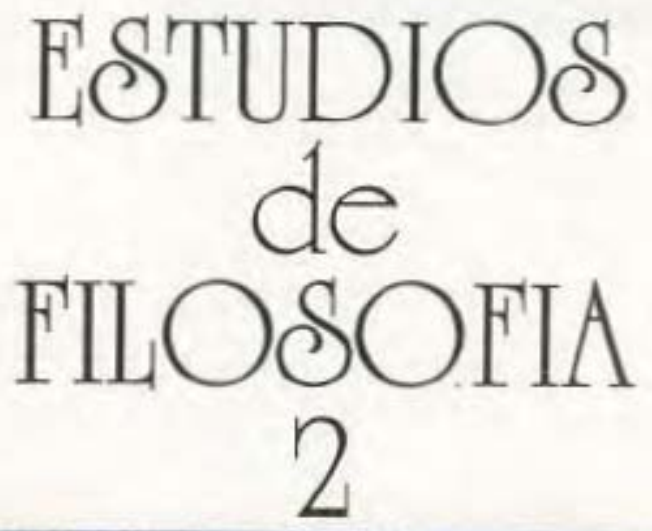




\section{LA HERMENEUTICA EN EL SIGLO XIX (Wilhelm Dilthey y Friedrich Nietzsche)}

La cuestión hermenéutica, es decir las cuestiones filosóficas que tratan del problema de la comprensión y de la interpretación de textos, de comportamientos sociales y de culturas ajenas, es con certeza uno de los problemas fundamentales del pensamiento filosófico del siglo XX. Filósofos tan distintos como Heidegger y Habermas, Gadamer y Derrida, para sólo mencionar algunos, tienen este cuestionamiento como punto común.

La relevancia de este tema para la filosofía actual fue motivo para elaborar en este seminario dos posiciones fundamentales en el contexto de esta discusión, representadas por la filosofía de Wilhelm Dilthey y de Friedrich Nietzsche. Para ambos la preocupación por la comprensión y la interpretación, en otras palabras, la cuestión de la constitución o de la construcción de 'sentido' era el tema sobresaliente, a pesar de que sus posiciones y respuestas son las más divergentes y opuestas. A la búsqueda y constitución Diltheyana del sentido, que tiene como base 'la vida', Nietzsche opone 'la filosofía del martillo', que hace evidente que 'sentido' es siempre el resultado de un acto de fuerza, un acto de una interpretación forzada.

La discusión de estas dos posiciones contradictorias con sus implicaciones y consecuencias teóricas, que se evidenciaron tanto en la temática hermenéutica como en la de la antropología filosófica y la filosofía de la historia, fueron tarea principal del seminario.

Al mismo tiempo, el análisis de la mencionada confrontación brindó elementos críticos importantes para entender el debate hermenéutico contemporáneo, así como la crítica postmoderna a la hermenéutica.

Los temas tratados y discutidos en el seminario fueron :
Schleiermacher y los orígenes de la hermenéutica en el siglo XIX (Texto: H.-G. Gadamer. Verdad y Método. Segunda parte, I, 1)

W. Dilthey y la hermenéutica (Texto: W. Dilthey, Orígenes de la Hermenéutica, en: W. Dilthey. El Mundo histórico. Obras completas. t. VII. H.-G. Gadamer. Verdad y Método. Segunda parte, I, 2)

W. Dilthey y la 'Filosofía de Vida' (Texto: W. Dilthey: La objectivación de la vida. Las categorías de la vida. En: W. Dilthey. El Mundo histórico).

W. Dilthey: La fundación de las ciencias del espiritu (Texto: W. Dilthey. Prólogo de la Introducción a las Ciencias del Espíritu; W. Dilthey. Ciencias de la Naturaleza y Ciencias del Espíritu. En: Psicología y teoría de conocimiento. Obras completas, t.IV)

Comprender y explicar (Textos: Ludwig Landgrebe. Sobre la Comprensión en las Ciencias del Espíritu. En: Fenomenología y Historia. Venezuela. Rudolf A. Makkreel. Dilthey und die interpretierenden

Wissenschaften: Die Rolle von Erklären und Verstehen. En: F. Rodi (Ed.), Dilthey Jahrbuch I, Göttingen 1983.

Karl-Otto Apel. Diltheys Unterscheidung von Erklären und Verstehen.

F. Nietzsche. La destrucción de la 'Historia' (Texto: F. Nietzsche. Consideraciones intempestivas).

F. Nietzsche. 'Sentido'e 'interpretación' (Textos: F. Nietzsche. Más allá del bien y del mal. F. Nietzsche. Genealogía de la moral).

F. Nietzsche. Una anti-hermenéutica (Textos: G. Deleuze. Nietzsche. G. Vattimo. Más allá del sujeto).

La actualidad de la cuestión hermenéutica (Texto: H.-G. Gadamer - J. Derrida: Un debate). 


\section{BIBLIOGRAFIA}

Apel, Karl-Otto, Diltheys Unterscheidung von Erklären und Verstehen. En: Orth E., Dilthey und die Philosophie der Gegenwart, Freiburg 1985. Transformaciones filosóficas, T. 1.

Bubner, Rüdiger, Fenomenología y hermenéutica. En: R. Bubner, La filosofía alemana contemporánea, Madrid 1984.

Coreth, Emerich, Cuestiones fundamentales de hermenéutica, Barcelona 1972.

Deleuze, Gilles, Nietzsche et la philosophie, Paris 1962.

--- Nietzsche, Paris 1965.

Dilthey, Wilhelm, Introducción a las Ciencias del Espíritu, México 1944.

.... Psicología y teoría del conocimiento. Obras completas, t. IV.

.... El Mundo histórico. Obras completas, t. VII.

Gadamer, Hans-Georg, Verdad y método.

Gadamer - Derrida, un debate. En: Ph. Forget (Ed.)

Text und Interpretation, München 1984.

Habermas, Jürgen (Ed.) Hermeneutik und Ideologiekritik, Frankfurt 1971.

Diltheys Theorie des Ausdrucksverstehens:
Ich-Identität und sprachliche Kommunikation. En: J. Habermas, Erkenntnis und Interesse, Frankfurt 1973.

Klossowski, Pierre, Nietzsche et le cercle vicieux. (Mercure de France) Paris 1969.

Nietzsche, Federico, Consideraciones intempestivas.

-... Más allá del bien y del mal.

---- Genealogía de la moral.

Palmer, R.E., Hermeneutics. Interpretation Theory in Shcleiermacher, Dilthey, Heidegger und Gadamer, Evanston 1972.

Patzig, Georg, Erklären und Verstehen, Neue Rundschau 3, 1973, 392-413.

Vattimo, Gianni, Más allá del sujeto. Nietzsche, Heidegger y la hermenéutica, Barcelona 1989.

\section{PARTICIPANTES}

Luisa Talledo Medrano, Aurelio Antonio Pérez Valerga, Richard Mario Celis Calero, Juan Francisco Núñez del Prado, Santiago Gallarday Morales, Irma Doris Navarro Soto, Leisley Lorena Ríos Espinosa, Ana Cecilia Monteagudo Valdes.

\section{SEMINARIO DE FILOSOFIA DE LA MATEMATICA}

\section{FILOSOFIA, LOGICA Y COMPUTACION}

\section{Instituto Riva-Agüero, 1991-I / II}

El seminario consiste en la lectura comentada y el análisis del libro Computability, Computable Functions, Logic, and The Foundations of Mathematics, de Richard L. Epstein y Walter A. Carnielli. Este texto trata problemas de lógica y matemáticas vinculados con sus fundamentos filosóficos y sus alcances en el campo de la informática.

Los autores intentan explicar el proceso en el que aparecen las paradojas de las ciencias formales, pues estiman que ese mismo mecanismo está a la base de la computación; así no sólo se comprende cuál es la estructura de las paradojas, sino quedan también en claro los fundamentos de la cibernética.

Por esta misma razón, la discusión con-
Profesor: Oscar Trelles $M$.

duce constantemente a tratar los problemas ontológicos subyacentes al discurso de la matemática, y algunos tópicos clásicos de la metafísica occidental (los universales, el a priori, la demostración) y sus conexiones con la teoría de conjuntos, las funciones, etc.

\section{PARTICIPANTES}

Profesores invitados: Luis Bacigalupo, Ramón García-Cobián, Diógenes Rosales.

Alumnos: Glenny Sotomayor, Gonzalo Gamio, Sandro D'Onofrio, entre otros.

Nota: El seminario continuará durante 1992, preparando la posible próxima visita a Lima de uno de los autores, el profesor W. Carnielli, planeada para 1993. 